\title{
THE INFLUENCE OF COLLECTIVISTIC PERSONAL VALUES ON THE FORMATION OF ENTREPRENEURIAL INTENTIONS
}

\section{Hueso, Juan Alberto}

PhD Candidate. Universidad de Sevilla. Department of Applied Economics. Av. Ramón y Cajal, 1. E41018 - Sevilla (Spain). juanalbertohueso@us.es

\section{Jaén, Inmaculada}

Assistant Professor. Universidad de Sevilla. Department of Applied Economics. Av. Ramón y Cajal, 1. E41018 - Sevilla (Spain). inmajaen@us.es

\section{Liñán, Francisco}

Professor in Entrepreneurship and Innovation.

Anglia Ruskin University. School of Management. East Road. CB1 1PT. Cambridge (United Kingdom). francisco.linan@anglia.ac.uk

Universidad de Sevilla. Department of Applied Economics. Av. Ramón y Cajal, 1. E41018 - Sevilla (Spain). flinan@us.es

\section{Basuki, Whysnianti}

Associate Professor. School of Business, Law and Communications. Southampton Solent University. SO14 OYN - Southampton (United Kingdom). whysnianti.basuki@solent.ac.uk

\section{Abstract}

This study analyses the specific role of collectivistic personal values as an antecedent of the entrepreneurial intention. While previous studies have almost exclusively focused on individualistic values, the influence of collectivistic values has remained largely ignored. We study this influence on a sample of 413 university students from the United Kingdom and Spain. The results are consistent in both countries. They show that the emphasis of collectivistic personal values triggers an indirect, negative effect on entrepreneurial intentions, through both the personal attitude and the perceived behavioural control. However, it also induces an indirect positive effect through subjective norms. The study 
indicates that the whole personal-value structure (and not only individualistic values) is influential in explaining the formation of entrepreneurial intentions.

Keywords: entrepreneurial intention; personal values; collectivistic values; theory of planned behaviour; structural equation modelling

\section{INTRODUCTION}

In recent decades, intention models have frequently been employed in entrepreneurship studies. Intention is considered the most immediate, and important variable for the prediction of the future behaviour of entrepreneurs (Adam and Fayolle, 2015). Literature on entrepreneurial intention is solid and extensive, with hundreds of papers analysing entrepreneurial intention models (Liñán and Fayolle, 2015). However, much remains to be ascertained regarding the way entrepreneurial intentions are formed. The recent literature (Liñán and Fayolle, 2015; Schlaegel and Koenig, 2014) has called for more empirical studies to provide an explanatory understanding of the underlying mechanisms within the entrepreneurial process.

Personal values represent potentially relevant variables in this respect (Morales et al., 2019), and in psychology research, they are important in explaining human actions (Bardi and Schwartz, 2003). These values have been regarded as one of the most significant drivers in guiding intentions and subsequent behaviour (Herek, 1986; Maio et al., 2001; Murray, Haddock and Zanna, 1996). According to Fayolle et al. (2014), personal values play a major role in entrepreneurship. In particular, much research has studied the individualistic personal values of entrepreneurs, by focusing on the consequences of entrepreneurial success, competitiveness, innovation and efficiency (Birch, 1981; Birch and MacCracken, 1983; Hayton, George and Zahra, 2002; Peterson, 1988; Reynolds and Freeman, 1986; Wagner and Moch, 1986). 
Yet individuals may stress the importance of a variety of basic values (Schwartz, 1992). Despite the main interests in individualistic values of entrepreneurship researchers (Morales et al., 2019), collectivistic values are also important as motivational goals and guiding principles for individuals. In this respect, one line of research focused on the moral responsibility and ethical behaviour of entrepreneurs (Amable, 2010; Anderson and Smith, 2007; Brenkert, 2009; Harris, Sapienza and Bowie, 2009; Scharff, 2016). It is argued that emphasis on collectivistic values may see the entrepreneur play a role in creating moral and ethical norms in new situations and contexts (Kaptein, 2017). This could imply a greater consideration of the consequences for others, both for the close group of relationships, and for society in general. In this vein, collectivistic values may make entrepreneurs provide their ventures with an element of sustainability, solidarity, business ethics, corporate social responsibility, gender equality and loyalty, among other factors (Barnett and Karson, 1987; Costa Jr, Terracciano and McCrae, 2001; Hemingway, 2005; Shephard, 2008).

Thus, the collectivistic values of potential entrepreneurs carry importance in the definition of their identity as entrepreneurs, and consequently their intention to start a venture. Nevertheless, there is still insufficient research on how personal values, in general, influence the decision-making processes of potential entrepreneurs. One of the few studies carried out in this field is that of Yang, Hsiung, \& Chiu (2015), though their focus was solely on the influence of personal values on personal attitudes.

In this study, the role of collectivistic personal values in the formation of the entrepreneurial intention is investigated. According to Ajzen's (1991) theory of planned behaviour (TPB), the entrepreneurial intention is developed from three motivational antecedents. The influence of the collectivistic personal values on all three antecedents, being personal attitude, subjective norms, and perceived behavioural control, is therefore analysed. 
Empirical analysis was conducted in two regions, from different countries (the UK and Spain), with these being clearly different in terms of history and culture. Nonetheless, they are both large, developed economies, exhibiting similar entrepreneurship rates. In $2017,9.3 \%$ of the working-age population in the UK were expected to start a business within the next 3 years (Hart et al., 2018). Despite the rate in Spain being lower, at $6.8 \%$ (Peña et al., 2018), the two economies have relatively high rates of potential entrepreneurship, suggesting that starting a business is considered a valued career option. Furthermore, the two countries share similar characteristics in that they both enjoy innovation-driven and mature economies (Liñán, Nabi and Krueger, 2013). These economies are shifting towards the service sector and catering for an increasingly more affluent population. As explained by Bosma et al. (2008), they are both focused on knowledge generation and the development of innovative, opportunity-seeking entrepreneurial activity.

Following this introduction, the paper proceeds as follows. First, the theoretical framework is presented, and our hypotheses regarding how collectivistic values affect the formation of the entrepreneurial intention are developed. The methodology and results are presented in the subsequent sections, with the paper finishing with the discussion and conclusion sections, wherein a reflection upon these results is included.

\section{THEORETICAL FRAMEWORK}

\subsection{Collectivistic personal values and the entrepreneurial intention}

Our study is based on an integration of values and intention theories. The Theory of Human Values, developed by Schwartz (1992), stresses the importance of personal values in affecting decision and action. Values are defined as desirable goals serving as guiding principles in people's lives (Schwartz, 1992; Schwartz and Bardi, 2001). These personal values orient decision-making and boost value-congruent behaviour (Bardi and 
Schwartz, 2003; De Dreu and Nauta, 2009; Schwartz, 2010, 2012). In this theory, it is assumed that values tend to be relatively stable over time (Bardi et al., 2009), and may therefore exert a long-lasting effect on motivation and intention (Morales et al., 2019; Yang, Hsiung and Chiu, 2015).

Widely used in the taxonomies of values found in the literature, Schwartz's theory is deemed the most well-developed (Yang, Hsiung and Chiu, 2015). Schwartz's (1994) value theory is based on a circular structure made up of ten different basic values: power, achievement, hedonism, stimulation, self-direction, universalism, benevolence, conformity, tradition, and security. These basic values may be grouped into four dimensions: self-enhancement, openness to change, self-transcendence, and conservation. The first two value-dimensions are more closely related to an individualistic orientation (Konsky et al., 2000). That is, they tend to be accentuated by individuals who consider themselves more as unique human beings deserving attention and satisfaction. In contrast, conservation and self-transcendence are associated with a less individualistic or more collectivistic orientation (Konsky et al., 2000). These tend to be emphasised by people who largely consider themselves to be part of a group. A graphic representation of this theory is presented in Figure 1.

\section{-- INSERT FIGURE 1 ABOUT HERE --}

The present research is focused on those collectivistic values included in the conservation and self-transcendence dimensions. That is, this research analyses the role of conformity, tradition, and security (conservation), universalism, and benevolence (self-transcendence). The conservation dimension underlines order, self-restriction, preservation of the past, and resistance to change. In turn, the self-transcendence 
dimension captures the values that emphasise concern for the welfare and interests of others (Schwartz, 2012).

Finally, these collectivistic values are linked to the entrepreneurial intention. Since intentions are central to the entrepreneurship process: they represent the first step in a succession of decisions and actions leading to becoming an entrepreneur (Bird, 1988; Kautonen, Van Gelderen and Fink, 2015) an entrepreneurial intention model is applied. Intentions depict the transformation of beliefs, perceptions and other exogenous factors into the outcome that immediately precedes the action itself (Ajzen, 2001). In short, intentions represent the most accurate proxy for the corresponding behaviour (Fayolle, Liñán and Moriano, 2014; Fishbein and Ajzen, 1975; Liñán and Chen, 2009; Miller et al., 2009; Schwarz et al., 2009).

The TPB, in particular, is the most commonly used framework in entrepreneurship research (Schlaegel and Koenig, 2014). It explains the intention to act out a behaviour as the result of three antecedents: the personal attitude (PA) towards this act, the subjective norms (SNs), and the perceived behavioural control (PBC).

Firstly, the PA refers to the degree to which a person has a positive or negative evaluation, or appraisal, of the entrepreneurial behaviour (Ajzen, 1991). Secondly, the SNs denote the support expected from the people of reference (family, friends, and so forth) if the individual decides to perform this behaviour. And thirdly, the PBC indicates the perceived ease or difficulty in carrying out the entrepreneurial action. More positive perceptions of these antecedents lead to a higher level of entrepreneurial intentions (Lee et al., 2011).

Therefore, the TPB is the second pillar upon which our theoretical framework is built. According to the TPB, other cognitive-level variables should affect intention indirectly, through its antecedents (Krueger, 2007). Personal values represent an example of such 
an indirect influence, and in particular, our focus centres on the values within the conservation and self-transcendence dimension.

\subsection{The conservation dimension}

The conservation dimension proposed by Schwartz (1992) involves accentuating the personal values of tradition, conformity, and security, and individuals that emphasise these values tend to avoid situations of uncertainty, and of change in their lives. It could be argued that these individuals have a deeply-rooted socio-cultural orientation (Yang, Hsiung and Chiu, 2015), tending to subordinate their own personal interests in favour of socially-imposed expectations. Individuals prioritising the personal value of tradition attach a high importance to respect, commitment, and acceptance of the customs and ideas of their culture or religion (Schwartz and Boehnke, 2004). In the same way, the assertion of conformity entails both, maintaining control over actions, inclinations, and impulses that may bother or harm others. Violation of social norms or expectations is also avoided (Schwartz and Boehnke, 2004). Additionally, the personal value of security implies the avoidance of risky situations, or of those implying uncertainty and change in the close environment (Yang, Hsiung and Chiu, 2015).

Conversely, the entrepreneur is identified with the continuous challenge of the status quo (Shane and Venkataraman, 2000) and the rupture of social expectations (De Clercq and Voronov, 2009). Such people fail to fit in with the values of the conservation dimension. Likewise, individuals who emphasise this conservation dimension are reluctant to perform actions that imply breaking with the customs and traditional ways of doing things (Yang, Hsiung and Chiu, 2015). Therefore, this information indicates that individuals highlighting conservation values might exhibit an unfavourable personal attitude towards entrepreneurship. Correspondingly, the following hypothesis can be established: 
H1a: Individuals accentuating conservation values (conformity, tradition, and security) will exhibit a less favourable Personal Attitude towards entrepreneurship.

Individuals who emphasise the conservation dimension attach great importance to the opinion of people of reference (parents, teachers, friends, etc.) and to the surrounding environment (religion, customs, traditions, and so forth) (Schwartz \& Boehnke, 2004). Hockerts (2017) affirms that a feeling of belonging to this close environment causes the person to expect a relationship of reciprocity. In this way, among the members of the closest group, and among the significant people within it, there is probably a 'moral obligation' of loyalty and support to the decisions of the other group members (Mair and Noboa, 2006). Therefore, just as individuals feel compelled to support the other members of their closest group of referents, so they would generally expect their family and other people of reference to support their decisions. In this way, this 'moral obligation' of loyalty and reciprocity with close referent people would cause individuals to expect to be supported when they decide to create a company. Thus, we propose the following hypothesis:

$\mathrm{H} 1 \mathrm{~b}$ : Individuals accentuating conservation values (conformity, tradition, and security) will exhibit more positive Subjective Norms regarding entrepreneurship.

Generally, individuals take one of two approaches to their decision-making process (Crowe and Higgins, 1997), by adopting one of the following regulatory foci: promotion or prevention. On the one hand, under the promotion regulatory focus, the individual is concerned with the advancement, growth, accomplishments, hopes, and aspirations that can be attained by performing a given behaviour. On the other, the prevention regulatory focus is concerned with safety, responsibilities, and obligations, in an effort to avert negative and/or uncertain outcomes. 
For the individual prioritising the conservation dimension, it is the harmony and stability of society, of relationships, and of the self that constitute crucial factors (Schwartz, 1994). In this respect, security is associated with an emphasis on "avoiding risky situations", and "avoiding everything that might go wrong". Furthermore, tradition and conformity imply respect for traditions and social norms (Schwartz, 1994). The perspective of starting up a company means making decisions, and carrying out behaviours that break with those traditions and social norms. Thus, for people who accentuate conservation values, the process of business creation is probably seen as a potential source of 'social sanction'.

Individuals accentuating the conservation dimension probably follow a prevention regulatory focus, rather than one of promotion. Consequently, they should be more conscious regarding the inherent difficulties that starting up a company involves (Brockner, Higgins and Low, 2004; Higgins, 1998). These individuals probably see new venture creation as a difficult and complex process. Accordingly, individuals emphasising conservation values should feel themselves less capable of successfully starting up a firm. These arguments lead us to propose the following hypothesis:

H1c: Individuals accentuating conservation values (conformity, tradition, and security) will exhibit a less favourable Perceived Behavioural Control.

\subsection{The self-transcendence dimension}

The dimension of self-transcendence encompasses the personal values of benevolence and universalism (Schwartz, 1992). Accentuating the benevolence value indicates that an individual tries to help other members of the closest group (relatives, ethnic group, close friends, and so on) and contributes to the welfare within the family and other primary groups (Schwartz, 2012). Subjects highlighting the personal value of universalism, on the other hand, stress the importance of tolerance, social justice, and equality (Schwartz, 1992). 
Notwithstanding, entrepreneurship is strongly characterised by an "egoistic passion" (Locke and Baum, 2007), which opposes the spirit of altruism, respect, tolerance, and the protection of the welfare of others (Hirschi and Fischer, 2013) ${ }^{1}$. Self-transcendent individuals are expected to appreciate the contribution to general social well-being as a major element, and should greatly value the rewards of time spent with their family, and with other significant people in their environment (Schwartz, 1992). In contrast, starting up a new venture implies a high commitment in terms of effort, resources, and time, and so for those emphasising the self-transcendence value dimension, entrepreneurship most likely represents a large opportunity cost (Yang et al., 2015). These individuals might, therefore, have a less favourable personal attitude towards entrepreneurship, and accordingly, the following hypothesis is proposed:

H2a: Individuals accentuating self-transcendence values (benevolence and universalism) will exhibit a less favourable Personal Attitude towards entrepreneurship.

Regarding the subjective norms, self-transcendent individuals considering the possibility of starting up a company have, among other motivations, the idea of helping others, both within the closest group (benevolence) and in broader society (universalism) (Schwartz, 1992). For this reason, individuals considering the option to start a venture as a way to help others likely expect people around them to share that vision of entrepreneurship. As a result, these potential entrepreneurs would expect to receive the support of the people who might benefit from the success of the new firm. Accordingly, the following hypothesis is proposed:

$\mathrm{H} 2 \mathrm{~b}$ : Individuals accentuating self-transcendence values (benevolence and universalism) will exhibit more positive Subjective Norms regarding entrepreneurship. 
Finally, stressing self-transcendental personal values implies recognition of the importance of contributing positively to the improvement of the close environment (Holland and Shepherd, 2013). This concern, regarding improving the environment and helping others, might generate a burden in the form of greater responsibility. These individuals should be more aware of the possible effects of their behaviour on other people close to them, on society in general, and on the natural environment, and involves a greater number of variables for consideration in the eventual process of venture creation. By taking all of these additional variables into account, these individuals probably consider the business venture process as a more complex and difficult target to achieve, and so the individual might perceive a lower level of behavioural control. Accordingly, the following hypothesis can be formulated:

H2c: Individuals accentuating self-transcendence values (benevolence and universalism) will exhibit a less favourable Perceived Behavioural Control.

\subsection{Research model}

Figure 2 presents an overview of our research model and the proposed hypotheses. This represents our conceptual framework where the motivational antecedents mediate the relationship of the conservation and self-transcendence dimension values, on the one hand, and the entrepreneurial intention, on the other.

-- INSERT FIGURE 2 ABOUT HERE --

\section{METHODOLOGY}

\subsection{Sample}

This study is based on survey data collected in two different regions: Hampshire in the UK, and Catalonia in Spain, with the two regions sharing similar economic and social 
conditions. In the United Kingdom, the data comes from a local university in the county of Hampshire, while in the Spanish sub-sample, it originates from several universities in the Catalonian region. Information of a more descriptive nature is presented in Table 1.

Given that young adults in the 25-to-35-year- age range with a higher level of education consistently exhibit some of the highest entrepreneurship participation rates (Singer, Herrington, \& Menipaz, 2018), university students make up our sample. Trained to experiment with their ideas in real-life situations, students learn and adapt them as they leverage who, and what they know to create valuable opportunities (Singer, Herrington and Menipaz, 2018).

-- INSERT TABLE 1 ABOUT HERE --

Questionnaires were distributed to students who attended business-related courses, and the British and Spanish samples presented similar characteristics. The target sample was made up of students enrolled in Undergraduate and Master programmes, with an initial 479 responses obtained. There were 61 respondents over the age of 35 , with these cases removed from the analysis due to their motivations and experience likely differing to those in the younger, target group. Additionally, 5 questionnaires were dropped due to their high level of missing data. The final sample, therefore, included 413 usable questionnaires, with 200 questionnaires collected in the UK, and 213 obtained from Spain.

As shown in Table 1, the general characteristics of the two subsamples were similar. The most notable differences related to the self-employment experience, which was substantially higher for the UK respondents ( $29 \%$ of UK respondents had this experience vs. $14 \%$ in Spain). In the same vein, the UK respondents reported a slightly higher educational level than their parents. With regard to parents with university qualifications, 
the percentage was similar (approximately $30 \%$ ) in the two subsamples. In Spain, it was much more common that parents were found to have only primary studies (around $30 \%$ of the respondents, whereas the corresponding percentage was less than $5 \%$ in the UK), with the same trend regarding secondary studies or vocational training (only $16-19 \%$ of respondents in Spain reported a parent in one of these categories vs. $25-30 \%$ for their UK counterparts).

\subsection{Measures}

The dependent variable is the entrepreneurial intention, which was measured through the well-established Entrepreneurial Intention Questionnaire (EIQ) (Liñán and Chen, 2009; Liñán, Moriano and Jaén, 2016). The scale was made up of 5 statements, with the response range varying from 0 to 6 , where 0 meant "Totally disagree", while 6 signified "Totally agree". As an example, one item was "I am willing to make any effort to become an entrepreneur". One item was intentionally reversed to prevent acquiescence bias.

The EIQ was also employed to measure the TPB antecedent variables: personal attitude (PA), subjective norms (SNs), and perceived behavioural control (PBC). Likert scales with a response range of 0 to 6 were also applied here, where 0 was "Not at all desirable" or "Totally disagree", and 6 indicated "Totally desirable" or "Totally agree". For the Personal Attitude, both the desirability of six specific outcomes and the expectation that these outcomes could be met through entrepreneurship were assessed. Example items for these outcomes include "starting a new business would involve being creative and innovative" and "to what extent is being creative and innovative desirable for you in general?". These responses were then multiplied to obtain a valuation of entrepreneurship.

Similarly, the Subjective Norms measure was obtained by multiplying the expected support from significant referent people (immediate family, close friends, and colleagues) by the motivation to comply with their opinions. Example items for this scale include "to 
what extent would your close friends agree if you decided to start a venture?" and "how do you value the opinion of your close friends in this regard?". In the case of Perceived Behavioural Control, a Likert-type scale with 6 statements was used, with responses ranging from 0 (totally ineffective) to 6 (fully effective). An example item for this scale would be "to what extent would you be able to effectively negotiate and maintain favourable relationships with potential investors and banks?".

Personal values were measured using Schwartz's Portrait Value Questionnaire (PVQ) (Schwartz et al., 2001). The PVQ measures value priorities, and is a scale comprised of 40 statements. The statements describe a person and ask the respondent to state the extent to which that person is similar to her/him. The response range varies from 0 (not at all like me) to 5 (very much like me). An example of these items is "Forgiving people who have hurt her/him is important to her/him. (S)he tries to see what is good in them and not to hold a grudge". The PVQ measures all ten personal values as proposed by Schwartz (1992). Specifically, a total of 23 items correspond to the formation of the collectivistic personal values composing the self-transcendence and conservation dimensions, and are grouped as follows: conformity (4 items), tradition (4 items), security (5 items), benevolence (4 items) and universalism (6 items).

Two dummy variables were included. The country dummy was coded as 1 for respondents in the UK, and 0 for those in Spain. This variable would control for any possible country differences in the level of any of the study variables. The level of individualism was also controlled for, since the overall Schwartz value structure includes individualistic values, together with collectivistic values (Schwartz, 1992, 1994, 2010, 2012). To compute this variable, the mean of all individualistic values was first calculated for each respondent, with this new variable then dichotomised as either 1 (for respondents with individualism levels higher than the mean) or 0 (for respondents with individualism levels lower than or equal to the mean). 
Despite the indication by Maxwell and Delaney (1993) that dichotomising continuous variables may be problematic, dichotomisation is carried out here for the individualism variable, given the existence of collinearity. Schwartz et al. (2012) reported the existence of frequent problems of high correlation and multicollinearity between the 10 basic values, particularly when a majority thereof are included together in the analysis. As explained by Falk and Miller (1992), multicollinearity in structural equation modelling is likely to lead to changes in the sign of coefficients, and to a reduction in significance levels ${ }^{2}$.

Additionally, age (in years) and gender (1=man, $0=$ woman) were included as controls on the TPB antecedents, and the entrepreneurial intention. Both age (Bönte, Falck and Heblich, 2009; Thorgren et al., 2016) and gender (Hechavarría et al., 2017; Klyver, Nielsen and Evald, 2013; Murnieks, Cardon and Haynie, 2020; Shinnar, Giacomin and Janssen, 2012; Shinnar et al., 2018) have been demonstrated as being substantial predictors of entrepreneurial intent and action, particularly in student samples (Shirokova, Osiyevskyy and Bogatyreva, 2016; Sieger and Monsen, 2015).

\subsection{Data analysis}

Structural equation modelling (SEM) was employed to test the hypotheses. This modelling enables the simultaneous examination of the relationships between measured variables and latent variables (Gefen, Straub \& Boudreau, 2000; Hair et al., 2017), and is most suitable when our model specification includes several dependent and exogenous variables, implying the need to estimate several regression equations simultaneously (Hair et al., 2017). More specifically, a Partial Least Squares SEM (PLSSEM or PLS path modelling) was applied. When the aim involves the development of new theories and exploratory research, then this statistical technique is more suitable than covariance-based SEM techniques (such as "Linear Structural Relations", LISREL) (Gefen, Straub \& Boudreau, 2000; Hair et al., 2017). As indicated by Sánchez-Franco \& Roldán (2005), PLS analysis provides results for both the measurement model (reliability 
and validity of indicators) and the structural model (hypothesised relationships). SmartPLS (v. 3.2.6) software was applied in the analysis.

\section{RESULTS}

\subsection{Measurement model}

The proposed model (Figure 2) was run for the full sample, including the country and individualism control variables, with the results presented in Figure 3. The Personal Attitude construct was defined as formative, since the specific motivations to become an entrepreneur had not to correlate with each other, and the aggregate attitude was formed as the summative evaluation of each of the motives (Hair et al., 2017). All the remaining constructs were measured as reflective, and in the case of the formative construct, meaningful and significant weights indicated sufficient reliability.

Firstly, the measurement model was verified for the full sample, following standard practice in the field (Hair et al., 2017). The reversed item in the entrepreneurial intention scale was therefore dropped due to its low loading. Similarly, the second item (pa2) in the personal attitude (PA) construct was eliminated, since the weight was negative and non-significant. The detailed results for the measurement model are reported in Table A1 in the Appendix. All the indicators in the remaining reflective constructs had loadings above the usual 0.7 threshold. Additionally, reliability was satisfactory (both Cronbach's alpha and Composite Reliability were above 0.7), as was construct validity (Average Variance Extracted, AVE, above 0.5). Discriminant validity was assessed through both the Fornell-Larcker criterion and the heterotrait-monotrait ratio, and was satisfactory for all the indicators in each construct.

\subsection{Structural model}

Once measurement validity was confirmed, the results from the structural model were analysed in order to test our hypotheses. Table 2 presents the path coefficients and 
significance levels for the full sample, and for each of the national subsamples. Table A2 in the Appendix reports the descriptive statistics and correlations between the latent variables in the model, and in this respect, the mean entrepreneurial intention in our sample is 3.33 (on a scale from 0 to 6 ), meaning the respondents report a slightly positive intention level (the mean is above the mid-point 3 in the scale).

Additionally, each of our country subsamples has been compared with several related measures in order to crosscheck its representativeness. In particular, the GUESSS survey reports entrepreneurial intention levels for samples of university students in different countries (Sieger et al., 2018). The levels for England (although not the UK) and Spain are 2.21 and 2.51 , respectively ${ }^{3}$. These levels are lower than those in our sample (3.56 and 3.13, respectively), but this may possibly be explained by the higher mean age of the GUESSS respondents (37.0 and 28.7 years, respectively, compared with that of approximately 26 years in our sample).

\section{-- INSERT FIGURE 3 ABOUT HERE --}

The model in Figure 3 includes the two dummy variables. The UK respondents exhibit $\mathrm{PA}$ and PBC that are marginally more positive than is the case for their Spanish counterparts. As per the other control variables, age is also positively related to PA and PBC. Meanwhile, gender is marginally significantly related to $\mathrm{SNs}$ and $\mathrm{El}$, and men, in particular, exhibit marginally higher intentions, whereas women expect to receive stronger support from referent others.

The results for the individualistic-value dummy show that individualism is positively related to subjective norms. This means that respondents who accentuate individualistic values tend to expect stronger support from their people of reference. The relationships to PA, PBC, and El are also positive, but not significant, and once the level of 
individualism is controlled for, the distinctive influence of collectivistic values can then be analysed.

Regarding the values in the conservation dimension, negative relationships with PA (H1a) and PBC (H1c) were expected. In the first case, the path coefficients were negative for all three values, of which two were significant (conformity-PA $=-0.110, p<0.05$; tradition-PA $=-0.153, p<0.05)$, while the third value is not significant (security-PA $=-$ 0.076). Thus, partial support for $\mathrm{H} 1 \mathrm{a}$ was found. Regarding PBC, the coefficients were negative for all three values, although not significant. Therefore, no support was found for $\mathrm{H} 1 \mathrm{c}$. Finally, regarding $\mathrm{H} 1 \mathrm{~b}$ (the relationship of conservation values with $\mathrm{SNs}$ ), Figure 3 provided some weak support for this hypothesis, since the Conformity-SN coefficient was positive and significant $(0.206, p<0.01)$, while the Security-SN $(0.074)$ and the Tradition-SN (0.006) were positive but not significant.

With the focus on $\mathrm{H} 2$, regarding self-transcendence values and intention antecedents, clear support for hypotheses H2b was found, since both benevolence-SN $(0.116$, $p<0.05)$ and universalism-SN $(0.137, p<0.05)$ were positive and significant, as expected. The negative relationships from benevolence and universalism to PA $(\mathrm{H} 2 \mathrm{a})$ and PBC $(\mathrm{H} 2 \mathrm{c})$ were also partially supported. In the case of PA, both path coefficients were negative, although only one was significant (Benevolence-PA $=-0.062$; not significant; Universalism-PA $=-0.143 ; p<0.05)$. For PBC, both coefficients were again negative, but only one was significant (Benevolence-PBC $=-0.127 ; \mathrm{p}<0.05$; Universalism-PBC $=$ 0.103; not significant). Hence, overall, partial support was found for $\mathrm{H} 2 \mathrm{a}$ and $\mathrm{H} 2 \mathrm{c}$.

Figure 3 also shows the path coefficients from the antecedents of intention to the entrepreneurial intention itself. As may be seen, they are fairly robust, with PA and PBC exhibiting positive and significant relationships of a similar size, while for SNs the relationship (although positive) is non-significant. These results are consistent with previous studies (Autio et al., 2001; Krueger, Reilly, \& Carsrud, 2000; Liñán \& Chen, 2009). 


\subsection{Multigroup analysis}

Finally, as a robustness check, a multigroup analysis was performed in order to compare the path coefficients for the Spanish and the UK subsamples. To this end, the country dummy had to be dropped. The individualist dummy variable was maintained as a control, as were age and gender. The results for the full sample are presented in Figure 4, while the correlations between the latent variables are included in Table A3 and A4 in the Appendix. As may easily be observed, these results are essentially the same as in Figure 3 , with the only difference worth noting found in the path coefficient from universalism to PBC, which is now marginally significant $(\beta=-0.115, p<0.1)$. For the sake of simplicity, the coefficients for age and gender are not shown, although they remain the same as in the previous model.

The path coefficients and significance levels for the multigroup analysis are presented in Table 2. Only four paths are significantly different in each sample, and in four other paths the difference is marginally significant. The effect of individualism on the TPB antecedents is stronger in the UK for PBC $\left(\left|\beta_{\text {Spain }}-\beta_{U K}\right|=0.418 ; p<0.01\right)$, for PA $\left(\mid \beta_{\text {Spain }}\right.$ $\left.-\beta_{u K} \mid=0.259, p<0.05\right)$, and marginally for SNs $\left(\left|\beta_{\text {Spain }}-\beta_{u K}\right|=0.220, p<0.1\right)$. Clearly, higher individualistic personal values are associated to more positive antecedents of intention in the UK, but not to those in Spain.

When the focus is placed on the hypothesised relationships, the differences can be observed as concentrated on the relationship between certain collectivistic values and both SNs and PBC. In the case of SNs, the path from Conformity is more positive (| $\beta_{\text {Spain }}$ $-\beta_{U K} \mid=0.249 ; p$-value $\left.<0.05\right)$ in the UK, as is marginally so for Universalism $\left(\mid \beta_{\text {Spain }}-\right.$ $\beta_{U K} \mid=0.176 ; p$-value $\left.<0.1\right)$. In turn, in the case of PBC, the path from Universalism is negative in Spain but positive in the UK $\left(\left|\beta_{\text {Spain }}-\beta_{U K}\right|=0.253\right.$; p-value $\left.<0.05\right)$. There are also marginally significant differences for Tradition-PBC $\left(\left|\beta_{\text {Spain }}-\beta_{U K}\right|=0.153 ; p\right.$ - 
value $<0.1)$ and Benevolence-PBC $\left(\left|\beta_{\text {Spain }}-\beta_{U K}\right|=0.185 ; p\right.$-value $\left.<0.1\right)$. Overall, the interpretation of these differences is that collectivistic values are more strongly related to higher SNs in the UK, whereas in Spain, they are more closely related to lower PBC (in particular, the self-transcendence values).

-- INSERT FIGURE 4 ABOUT HERE --

-- INSERT TABLE 2 ABOUT HERE --

In each subsample, the results are consistent with the full model presented in Section 4.2 above, although fewer path coefficients are significant, which is probably due to the smaller sample sizes. The first set of hypotheses relates to conservation values (conformity, tradition, and security) and their relationship with TPB antecedents. In the case of $\mathrm{H} 1 \mathrm{a}$, all the coefficients are negative, as expected, but none are significant. For $\mathrm{H} 1 \mathrm{~b}$, five out of six coefficients are positive, as expected (the exception being Tradition$S N_{\text {Spain }}=-0.034$, not significant) and, in the UK sample, two of the coefficients are either significant (conformity-SN $\left.\mathrm{NK}_{\mathrm{U}}=0.341, \mathrm{p}<0.001\right)$ or marginally so $\left(\right.$ Security-SN $\mathrm{UK}_{\mathrm{K}}=0.169$, $\mathrm{p}<0.1)$. As per $\mathrm{H} 1 \mathrm{c}$, the three path coefficients for Spain are negative, while the coefficients for the UK are positive, although none are significant.

The second set of hypotheses concerns the influence of self-transcendence values (benevolence and universalism) on the TPB antecedents. Regarding PA $(\mathrm{H} 2 \mathrm{a})$, the coefficients are negative for both personal values in both subsamples, but only one coefficient is significant (Universalism-PAspain $=-0.230, p<0.05$ ). In the case of PBC $(\mathrm{H} 2 \mathrm{c})$, the coefficients are negative and significant for the Spanish subsample (Benevolence-PBC $_{\text {Spain }}=-0.211, p<0.05$; Universalism-PBC $\left.{ }_{\text {Spain }}=-0.230, p<0.05\right)$, but 
they are non-significant for the UK subsample. Finally, with respect to $H 2 b$, the coefficients are positive in both subsamples, though only significant for the UK. The path from Benevolence is marginally significant (Benevolence-SN $\left.N_{U K}=0.127, p<0.1\right)$, whereas the path from Universalism is significant (Universalism-SN $N_{U K}=0.229, p<0.05$ ).

\section{DISCUSSION}

The main contribution of this research is the highlighting of the relationship between collectivistic personal values and the TPB antecedent variables and, consequently, the entrepreneurial intention. The findings from this study indicate that Schwartz's (1992, 1994) and Ajzen's (1991) theoretical frameworks are highly compatible in the prediction of entrepreneurial intentions, and is of major interest, serving to confirm previous studies that have carried out this integration (Liñán et al., 2016; Morales et al., 2019). The empirical analysis is carried out through examination of a sample of the working-age student population from the United Kingdom and Spain, with results from the present research suggesting that collectivistic personal values could represent a major obstacle to start-up rates. More specifically, accentuation of these values leads to a less favourable evaluation (PA) and less perceived ability and control (PBC) regarding the process of starting up. This, in turn, would imply a lower entrepreneurial intention.

In the relationship between collectivistic personal values and SNs, the expected positive effect is found. Nevertheless, it was also found that SNs are not significantly related to El, which is consistent with the previous research (Armitage \& Conner, 2001; Autio et al., 2001; Liñán \& Chen, 2009; Moriano et al., 2012; Santos, Landström, \& Fayolle, 2017). In this respect, it could be worth considering alternative specifications of the entrepreneurial intention model in which SNs are proposed as having an effect on PA and PBC (Fretschner and Weber, 2013; Liñán and Chen, 2009). This might serve to 
compensate for the negative relationship between collectivistic values and PA/PBC. Future research could analyse this possibility.

Subjective norms are measured by multiplying normative beliefs with the motivation to comply with these beliefs (Ajzen, 1991; Ajzen and Fishbein, 1980). Normative beliefs represent the so-called social pressures to perform (or not to perform) the entrepreneurial behaviour (starting up) (Ajzen, 1991). On the other hand, motivation to comply represents the personal urge to abide the opinions of other people of reference (Ajzen, 1991; Belchior and Liñán, 2017). It may be the case that the conservation and self-transcendence dimensions are positively related with the motivation-to-comply element of the subjective norms. In this case, individuals accentuating collectivistic values will be more inclined to follow recommendations made by other people of reference, but will not necessarily expect these referent people to support their entrepreneurial aspirations (the normative-belief element of the subjective norms).

Additionally, the positive relationship hypothesised herein may be compensated by another negative influence that has been overlooked here. For instance, potential entrepreneurs may have a conflicting view of their referent people. As mentioned above, they may expect support based on the "moral obligation" towards in-group members (Hockerts, 2017), but may also think that these people of reference will not heartily endorse the idea of the individual starting up. These mixed feelings could explain the lack of significant results, as well as the differences found between the two countries. It may be argued that the influence of social norms on entrepreneurial intentions is much broader, and more complex, than that of the other two TPB variables. That is, the SNs seem to exhibit a nature different to that of PA and PBC. Future research should clarify this relationship through a more specifically-designed research analysis.

Related to this difference, previous research suggests that the relative strength of the TPB antecedents in predicting entrepreneurial intention may differ depending on the industry and national sample captured in the study (Kautonen et al., 2015; Kolvereid and 
Isaksen, 2006; Krueger et al., 2000). In this regard, certain conflicting results exist. For instance, certain studies find a significant influence of SNs on entrepreneurial intention (Kautonen et al., 2015; Kolvereid and Isaksen, 2006), while others (as is our case) find no such influence (Liñán et al., 2016; Moriano et al., 2012).

The possibility exists that the specific personal-value structure acts as a moderator in these relationships ${ }^{4}$. In this respect, Sieger and Monsen (2015) found that controllability perceptions, which could be related to self-direction values, might moderate the attitudeintention relation. Based on our results, accentuating collectivistic values decreases PA and PBC, but increases SN perceptions. At the same time, however, these values could also weaken the influence of PA/PBC and/or strengthen the influence of SNs on entrepreneurial intentions. This may be so since, for people accentuating collectivistic values, the opinion of their group members could be more influential on the entrepreneurial intention than may be the case for people emphasising individualistic values (Moriano et al., 2012). In this respect, Shinnar et al. (2018), found that women are less likely than men to act on their intentions. Based on our results, the different structures of values could constitute a significant moderator that explains this difference, since women and men tend to exhibit different priorities for their values (Gupta, Turban and Pareek, 2013). Future research could analyse whether specific personal values (either alone or in combination with other values) moderate the relationship between TPB antecedents and entrepreneurial intention.

\subsection{Implications}

Schwartz's $(1992,1994)$ value theory proposes a circular structure of values. Emphasis on certain values is associated with a low importance being attached to the opposing values, and with this idea in mind, most research to date has focused on individualistic personal values, by assuming that the relevance of the opposing collectivistic values will be low, and that they need not be considered. In turn, our research shows that, even after controlling for the level of individualistic personal values, the stress attached to 
collectivistic values is also important and has an effect on the motivational antecedents of intention. That is, for any given level of importance ascribed to individualistic values, a higher relevance of self-transcendence or conservation values will imply a less favourable personal attitude, and a lower perceived behavioural control, together with SNs of a more favourable nature.

This carries significant implications for entrepreneurship scholars and policy-makers. The whole value structure of individuals (and not only certain values, such as selfdirection, stimulation, and achievement) is relevant in the assessment of their entrepreneurial potential. Nevertheless, further research is needed to more thoroughly understand the interaction between the values in each value dimension.

In particular, self-transcendence values are negatively associated with PA and PBC. However, the preoccupation regarding the welfare of others (Schwartz, 1994), which is inherent to these values, is clearly related to social entrepreneurship. In this regard, there is a contemporary discussion on morals and ethics involving more sustainable enterprises (Anderson and Smith, 2007). There have also been some calls to bring about a discourse that is more closely related to morality and ethics in entrepreneurship research (Brenkert, 2009; Dey and Steyaert, 2016; Harris, Sapienza and Bowie, 2009; Morris et al., 2002). In this respect, previous findings show that people highlighting individualistic personal values place less emphasis on understanding the reasoning and judgment behind the moral perspective that individual agents assume (Dey and Steyaert, 2016; Gielnik et al., 2015). By contrast, collectivistic values promote thoughts, feelings, and behaviour towards connecting with others, and within one's own group (Triandis and Gelfand, 2012). From this perspective, there may be some very relevant qualitative differences between entrepreneurs high in collectivistic values, and those who do not prioritise these values. Arguably, therefore, accentuating these collectivistic values may decrease the chances of starting up, although doing so may contribute towards a more 
socially responsible behaviour on the part of the entrepreneur. Future research could provide new insights in this respect.

There is an obvious application of these results, if confirmed, to entrepreneurship education. Despite the relative stability of values (Bardi et al., 2009), they are not completely fixed, and may be modified through, for instance, education (Myyry, Juujärvi and Pesso, 2013). Education opens up the mind to new knowledge and helps develop fresh and new personal perspectives, which often then make the individual reconsider her/his value priorities (Schwartz, 2010; 2012). In the particular case of business schools, there is evidence of value change even when no specific value-transmitting activities were included in the academic curriculum (Arieli, Sagiv and Cohen-Shalem, 2016). This process takes place not only through purposeful actions by teachers, but also through peer interaction, which constitutes a key mechanism in value socialisation (Racko, Strauss and Burchell, 2017). More generally, Bardi and Goodwin (2011) identified several mechanisms leading to value change, including priming, adaptation, identification, consistency maintenance, and direct persuasion attempts. Most of these mechanisms are likely to be present in educational programmes. In this respect, Westhead and Solesvik (2016) found that women and men benefit differently from entrepreneurship education. These differences could be explained by the initial personalvalue structure, and the value-change during education.

Value-transmitting training activities, therefore, may be devised to contribute towards modifying the value structure of the participants. This is in line with previous research that insisted on the importance of developing a more conscious entrepreneurial mind-set (Krueger, 2007; McGrath and MacMillan, 2000; McMullen and Shepherd, 2006). Nevertheless, further research that would enable the most promising combination of values is still required, not only for the promotion of entry into entrepreneurship, but, at the same time, for the fostering of responsible and sustainable behaviour as an entrepreneur. 
The comparison with the general GUESSS results for England and Spain have shown that our sample of younger postgraduate students exhibit higher intentions than is the case for a wider sample of older students (possibly having returned to education after some experience at work). This raises another interesting point regarding the predictive ability in the theory of planned behaviour (TPB). A higher entrepreneurial intention need not turn into action. Certain authors, such as Liñán \& Chen (2009) and Van Gelderen, Kautonen, \& Fink (2015), typically find that the motivational antecedents explain 40 $60 \%$ of the variance in the entrepreneurial intention, and though this renders the TPB framework the most accurate model for the prediction of intentions (Schlaegel and Koenig, 2014), Kautonen et al. (2015) report that the ability of this model to predict behaviour is considerably lower: typically in the range of $20-30 \%$.

Hence, a substantial proportion of unexplained behaviour that requires clarification remains. The value structure, including both individualistic and collectivistic value dimensions, may hold the key to unlocking this question. In this respect, recent research has analysed the role of security as a job motivation (Delanoë-Gueguen and Liñán, 2019), which is closely linked to the personal value of security. Their results indicate that a security motivation not only decreases intention, but also has a direct negative effect on behaviour. Again, further research should be carried out to explore the role of personal values (both collectivistic and individualistic) in the intention-behaviour link.

\subsection{Limitations}

The present study, like any other, is not without its limitations. The sample is restricted to two regions in two different developed countries. Cultural studies have shown that individualistic values tend to prevail in these countries, while collectivistic values predominate in developing countries (Schwartz and Bardi, 2001). A sample that originates from a less developed economy may yield disparate results. Similarly, even 
though young adults are especially inclined to start a new venture, other groups of the population are also relevant in this respect. The results found here may be inconsistent with those from a sample of an older population, or one with different characteristics (e.g., a lower level of education). For these reasons, future research should test the proposed research model on various countries and population segments prior to any generalisations being drawn.

\section{CONCLUSION}

To the best of our knowledge, this is one of the very first studies that analyses the relationship between collectivistic personal values and entrepreneurial intention. The results offer certain relevant insights concerning the importance of these values in the entrepreneurial process. These values are negatively related to attraction and perceived control towards entrepreneurship, but positively related to subjective norms. This influence holds fast, despite controlling for the level of individualism of the respondents, and hence, collectivistic values exert an influence of their own on the formation of entrepreneurial intentions, over and above that of the more widely studied individualistic values.

These results, if confirmed, may substantially transform the study of values in entrepreneurship. The search for the 'key' values that increase intention could well prove futile. Instead, it may turn out to be the specific combination of all (individualistic and collectivistic) values that is relevant in this process. Furthermore, the implications of accentuating values, such as universalism and benevolence, may be related to social entrepreneurship intentions and behaviour. The present study, therefore, opens up several highly interesting avenues for further research, and we trust that the entrepreneurship research community will find them to be worthy of exploration. 


\section{NOTES}

${ }^{1}$ Social entrepreneurship could be a possible exception here. However, our argument refers to entrepreneurship in general.

${ }^{2}$ The analysis was carried out with the continuous individualist-value dummy variable, but strong collinearity was present. For this reason, a dichotomic individualistic dummy variable had to be used.

${ }^{3}$ The figures are corrected to make the response range comparable to that in our sample, since the GUESSS survey reply options range from 1 to 7 , while our questionnaire options range from 0 to 6 .

${ }^{4}$ We are most grateful to an anonymous reviewer for pointing out this issue. 


\section{REFERENCES}

Adam A and Fayolle A (2015) Bridging the entrepreneurial intention-behaviour gap: the role of commitment and implementation intention. International Journal of Entrepreneurship and Small Business 25(1): 36-54.

Ajzen I (1991) The theory of planned behaviour. Organizational Behavior and Human Decision Processes 50(2): 179-211.

Ajzen I (2001) Nature and operation of attitudes. Annual Review of Psychology 52(1): $27-58$.

Ajzen I and Fishbein M (1980) Understanding attitudes and predicting social behaviour. Englewood Cliffs, NJ: Prentice-Hall.

Amable B (2010) Morals and politics in the ideology of neo-liberalism. Socio-Economic Review. 9(1): 3-30.

Anderson AR and Smith R (2007) The moral space in entrepreneurship: an exploration of ethical imperatives and the moral legitimacy of being enterprising. Entrepreneurship and Regional Development 19(6): 479-497.

Arieli S, Sagiv L and Cohen-Shalem E (2016) Values in business schools: The role of self-selection and socialization. Academy of Management Learning and Education, Academy of Management 15(3): 493-507.

Armitage CJ and Conner M (2001) Efficacy of the theory of planned behaviour: A metaanalytic review. British Journal of Social Psychology 40(4): 471-499.

Autio EH, Keeley R, Klofsten M, Parker GGC and Hay M (2001) Entrepreneurial intent among students in Scandinavia and in the USA. Enterprise and Innovation Management Studies 2(2):145-160.

Bardi A and Goodwin R (2011) The dual route to value change: Individual processes 
and cultural moderators. Journal of Cross-Cultural Psychology 42(2): 271-287.

Bardi A and Schwartz SH (2003) Values and behavior: Strength and structure of relations. Personality and Social Psychology Bulletin 29(10): 1207-1220.

Bardi A, Lee JA, Hofmann-Towfigh N and Soutar G (2009) The structure of intraindividual value change, Journal of Personality and Social Psychology 97(5): 913.

Barnett JH and Karson MJ (1987) Personal values and business decisions: An exploratory investigation. Journal of Business Ethics 6(5): 371-382.

Belchior RF and Liñán F (2017) Individual and cultural values as psychosocial cognitive antecedents and moderators of entrepreneurial intentions. In: Santos SC, Caetano A, Mitchell C, Landstrom $\mathrm{H}$ and Fayolle A (eds) The Emergence of Entrepreneurial Behaviour: Intention, Education and Orientation. Cheltenham UK and Northampton USA: Edward Elgar Publishing, 66-87.

Birch DL (1981) Who creates jobs?, The Public Interest (65): 3-14.

Birch DL and MacCracken SJ (1983) The small business share of job creation: lessons learned from the use of a longitudinal file. MIT Program on Neighborhood and Regional Change

Bird B (1988) Implementing entrepreneurial ideas: The case for intention. Academy of Management Review 13(3): 442-453.

Bönte W, Falck O and Heblich S (2009) The Impact of Regional Age Structure on Entrepreneurship. Economic Geography 85(3): 269-287.

Bosma N, Acs ZJ, Autio E and Levieand J (2008) Global entrepreneurship monitor, 2008 Executive report. Report, Global Entrepreneurship Research Consortium (GERA).

Brenkert GG (2009) Innovation, rule breaking and the ethics of entrepreneurship. 
Journal of Business Venturing 24(5): 448-464.

Brockner J, Higgins ET and Low MB (2004) Regulatory focus theory and the entrepreneurial process. Journal of Business Venturing 19(2): 203-220.

De Clercq D and Voronov M (2009) The role of cultural and symbolic capital in entrepreneurs ability to meet expectations about conformity and innovation. Journal of Small Business Management 47(3): 398-420.

Costa Jr PT, Terracciano A and McCrae RR (2001) Gender differences in personality traits across cultures: robust and surprising findings. Journal of Personality and Social Psychology 81(2): 322.

Crowe E and Higgins ET (1997) Regulatory focus and strategic inclinations: Promotion and prevention in decision-making. Organizational Behavior and Human Decision Processes 69(2): 117-132.

Delanoë-Gueguen S and Liñán F (2019) A longitudinal analysis of the influence of career motivations on entrepreneurial intention and action. Canadian Journal of Administrative Sciences 36(4): 527-543.

Dey P and Steyaert C (2016) Rethinking the space of ethics in social entrepreneurship: Power, subjectivity, and practices of freedom. Journal of Business Ethics 133(4): $627-641$.

De Dreu CKW and Nauta A (2009) Self-interest and other-orientation in organizational behavior: implications for job performance, prosocial behavior, and personal initiative. Journal of Applied Psychology 94(4): 913-926.

Falk R and Miller NB (1992) A primer for soft modeling. Akron (OH): University of Akron Press.

Fayolle A, Liñán F and Moriano JA (2014) Beyond entrepreneurial intentions: values and motivations in entrepreneurship. International Entrepreneurship and 
Management Journal 10(4): 679-689.

Fishbein M and Ajzen I (1975) Belief, Attitude, Intention, and Behaviour: An Introduction to Theory and Research. Reading (MA): Addison-Wesley.

Fretschner M and Weber S (2013) Measuring and understanding the effects of entrepreneurial awareness education. Journal of Small Business Management 51(3): 410-428.

Gefen D, Straub D and Boudreau MC (2000) Structural equation modeling and regression: Guidelines for research practice. Communications of the Association for Information Systems 4(1): 7.

Gielnik MM, Frese M, Kahara-Kawuki A, Katono IW, Kyejjusa S, Ngoma M et al. (2015) Action and action-regulation in entrepreneurship: Evaluating a student training for promoting entrepreneurship. Academy of Management Learning and Education 14(1): 69-94.

Gupta VK, Turban DB and Pareek A (2013) Differences Between Men and Women in Opportunity Evaluation as a Function of Gender Stereotypes and Stereotype Activation. Entrepreneurship Theory and Practice 37(4): 771-788.

Hair JF, Hult GTM, Ringle CM and Sarstedt M (2017) A primer on partial least squares structural equation modeling (PLS-SEM). Los Angeles: Sage Publications.

Harris JD, Sapienza HJ and Bowie NE (2009) Ethics and entrepreneurship. Journal of Business Venturing 24(5): 407-418.

Hart M, Bonne K, Levie J and Heery L (2018). Global Entrepreneurship Monitor, United Kingdom 2017 monitoring report. Report, Global Entrepreneurship Research Consortium (GERA).

Hayton JC, George G and Zahra SA (2002) National culture and entrepreneurship: A review of behavioral research. Entrepreneurship Theory and Practice 26(4): 33-52. 
Hechavarría DM, Terjesen SA, Ingram AE, Renko M, Justo R and Elam A (2017) Taking care of business: the impact of culture and gender on entrepreneurs' blended value creation goals. Small Business Economics 48(1): 225-257.

Hemingway CA (2005) Personal values as a catalyst for corporate social entrepreneurship. Journal of Business Ethics 60(3): 233-249.

Henseler J, Dijkstra TK, Sarstedt M, Ringle CM, Diamantopoulos A, Straub DW et al. (2014) Common beliefs and reality about PLS: Comments on Rönkkö and Evermann. Organizational Research Methods 17(2): 182-209.

Herek GM (1986) The instrumentality of attitudes: Toward a neofunctional theory. Journal of Social Issues 42(2): 99-114.

Higgins ET (1998) Promotion and prevention: Regulatory focus as a motivational principle. Advances in Experimental Social Psychology (30): 1-46.

Hirschi A and Fischer S (2013) Work values as predictors of entrepreneurial career intentions. Career Development International 18(3): 216-231.

Hockerts K (2017) Determinants of social entrepreneurial intentions: Entrepreneurship Theory and Practice 41(1): 105-130.

Holland DV and Shepherd DA (2013) Deciding to persist: Adversity, values, and entrepreneurs decision policies. Entrepreneurship Theory and Practice 37(2): 331358.

Kaptein M (2017) The living code: Embedding ethics into the corporate DNA. London: Routledge.

Kautonen T, Van Gelderen M and Fink M (2015) Robustness of the theory of planned behavior in predicting entrepreneurial intentions and actions. Entrepreneurship Theory and Practice 39(3): 655-674.

Klyver K, Nielsen SL and Evald MR (2013) Women's self-employment: An act of 
institutional (dis)integration? A multilevel, cross-country study. Journal of Business Venturing 28(4): 474-488.

Kolvereid L and Isaksen E (2006) New business start-up and subsequent entry into self-employment. Journal of Business Venturing 21(6): 866-885.

Konsky C, Eguchi M, Blue J and Kapoor S (2000) Individualist-collectivist values: American, Indian and Japanese cross-cultural study. Intercultural Communication Studies 9(1): 69-84.

Krueger NF (2007) The cognitive infrastructure of opportunity emergence. In: Cuervo Á, Ribeiro D and Roig S (eds) Entrepreneurship. Berlin: Heidelberg, pp: 185-206. Krueger NF, Reilly MD and Carsrud AL (2000) Competing models of entrepreneurial intentions. Journal of Business Venturing 15(5): 411-432.

Lee L, Wong PK, Der Foo M and Leung A (2011) Entrepreneurial intentions: The influence of organizational and individual factors. Journal of Business Venturing 26(1): 124-136.

Liñán F and Chen Y (2009) Development and Cross-Cultural application of a specific instrument to measure entrepreneurial intentions. Entrepreneurship Theory and Practice 33(3): 593-617.

Liñán F and Fayolle A (2015) A systematic literature review on entrepreneurial intentions: citation, thematic analyses, and research agenda. International Entrepreneurship and Management Journal 11(4): 907-933.

Liñán F, Moriano JA and Jaén I (2016) Individualism and entrepreneurship: Does the pattern depend on the social context?. International Small Business Journal 34(6): 760-776.

Liñán F, Nabi G and Krueger N (2013) British and Spanish entrepreneurial intentions: A comparative study. Revista de Economía Mundial (33): 73-103. 
Locke EA and Baum JR (2007) Entrepreneurial motivation. The Psychology of Entrepreneurship, 93-112.

Maio GR, Olson JM, Allen L and Bernard MM (2001) Addressing discrepancies between values and behavior: The motivating effect of reasons. Journal of Experimental Social Psychology 37(2): 104-117.

Mair J and Noboa E (2006) Social Entrepreneurship: How Intentions to Create a Social Venture are Formed. In: Mair J, Robinson J and Hockerts K (eds) Social Entrepreneurship. London: Palgrave Macmillan, 121-135.

Maxwell SE and Delaney HD (1993). Bivariate median splits and spurious statistical significance. Psychological Bulletin 113(1): 181-190

McGrath RG and MacMillan IC (2000) The entrepreneurial mindset: Strategies for continuously creating opportunity in an age of uncertainty. Boston: Harvard Business School Press.

McMullen JS and Shepherd DA (2006) Entrepreneurial action and the role of uncertainty in the theory of the entrepreneur. Academy of Management Review. 31(1): 132-152.

Miller BK, Bell JD, Palmer M and Gonzalez A (2009) Predictors of entrepreneurial intentions: a quasi-experiment comparing students enrolled in introductory management and entrepreneurship classes. Journal of Business and Entrepreneurship 21(2): 39-62.

Morales C, Holtschlag C, Masuda AD and Marquina P (2019). In which cultural contexts do individual values explain entrepreneurship? An integrative values framework using Schwartz's theories. International Small Business Journal 37(3): 241-267.

Moriano JA, Gorgievski M, Laguna M, Stephan U and Zarafshani K (2012) A cross- 
cultural approach to understanding entrepreneurial intention. Journal of Career Development 39(2): 162-185.

Morris MH, Schindehutte M, Walton J and Allen J (2002) The ethical context of entrepreneurship: Proposing and testing a developmental framework. Journal of Business Ethics 40(4): 331-361.

Murnieks CY, Cardon MS and Haynie JM (2020) Fueling the fire: Examining identity centrality, affective interpersonal commitment and gender as drivers of entrepreneurial passion. Journal of Business Venturing 35(1).

Murray SL, Haddock G and Zanna MP (1996) On creating value-expressive attitudes: An experimental approach. In: Seligman C, Olson JM and Zanna MP (eds) The Psychology of Values: The Ontario Symposium. Hillsdale NJ: Erlbaum, 107-133.

Myyry L, Juujärvi S and Pesso K (2013) Change in values and moral reasoning during higher education. European Journal of Developmental Psychology 10(2): 269-284.

Peña I, Guerrero M, González-Pernía JL and Montero J (2018) Global Entrepreneurship Monitor Informe GEM España 2017-2018. Report, University of Cantabria, Spain.

Peterson R (1988) Understanding and encouraging entrepreneurship internationally. Journal of Small Business Management 26(2): 1.

Racko G, Strauss K and Burchell B (2017). Economics education and value change: The role of program-normative homogeneity and peer influence. Academy of Management Learning and Education 16(3): 373-392.

Reynolds PD and Freeman S (1986) Pennsylvania new firm study, Vol. two: New firm contributions to Pennsylvania. Philadelphia: University of Pennsylvania, Wharton School.

Sánchez-Franco MJ and Roldán JL (2005) Web acceptance and usage model: A 
comparison between goal-directed and experiential web users. Internet Research 15(1): 21-48.

Santos SC, Landström H and Fayolle A (2017) The Emergence of Entrepreneurial Behaviour: Intention, Education and Orientation. USA: Edward Elgar Publishing.

Scharff C (2016) The psychic life of neoliberalism: Mapping the contours of entrepreneurial subjectivity. Theory, Culture and Society 33(6): 107-122.

Schlaegel C and Koenig M (2014) Determinants of entrepreneurial intent: a metaanalytic test and integration of competing models. Entrepreneurship Theory and Practice 38(2): 291-332.

Schwartz SH (1992) Universals in the content and structure of values: Theoretical advances and empirical tests in 20 countries. Advances in Experimental Social Psychology (25): 1-65.

Schwartz SH (1994) Are there universal aspects in the structure and contents of human values?. Journal of Social Issues 50(4): 19-45.

Schwartz SH (2008) Cultural value orientations: Nature and implications of national differences. Moscow: Publishing house of SU HSE.

Schwartz SH (2010) Basic values: How they motivate and inhibit prosocial behavior, In: Mikulincer M and Shaver PR (eds) Prosocial motives, emotions, and behavior: The better angels of our nature. Washington: American Psychological Association, 2652.

Schwartz SH (2012) An overview of the Schwartz theory of basic values. Online Readings in Psychology and Culture 2(1): 11.

Schwartz SH and Bardi A (2001) Value hierarchies across cultures: Taking a similarities perspective. Journal of cross-cultural psychology 32(3): 268-290. 
Schwartz SH and Boehnke K (2004) Evaluating the structure of human values with confirmatory factor analysis. Journal of Research in Personality 38(3): 230-255.

Schwartz SH, Cieciuch J, Vecchione M, Davidov E, Fischer R, Beierlein C et al. (2012) Refining the theory of basic individual values. Journal of Personality and Social Psychology 103(4): 663.

Schwartz SH, Melech G, Lehmann A, Burgess S, Harris M and Owens V (2001) Extending the cross-cultural validity of the theory of basic human values with a different method of measurement. Journal of Cross-Cultural Psychology 32(5): $519-542$.

Schwarz EJ, Wdowiak MA, Almer-Jarz DA and Breitenecker RJ (2009) The effects of attitudes and perceived environment conditions on students entrepreneurial intent: An Austrian perspective. Education+ Training 51(4): 272-291.

Shane S and Venkataraman S (2000) The promise of entrepreneurship as a field of research. Academy of Management Review 25(1): 217-226.

Shephard K (2008) Higher education for sustainability: seeking affective learning outcomes. International Journal of Sustainability in Higher Education 9(1): 87-98.

Shinnar RS, Giacomin O and Janssen F (2012) Entrepreneurial Perceptions and Intentions: The Role of Gender and Culture. Entrepreneurship Theory and Practice 36(3): 465-493.

Shinnar RS, Hsu DK, Powell BC and Zhou H (2018) Entrepreneurial intentions and start-ups: Are women or men more likely to enact their intentions?. International Small Business Journal 36(1): 60-80.

Shirokova G, Osiyevskyy O and Bogatyreva K (2016) Exploring the intention-behavior link in student entrepreneurship: Moderating effects of individual and environmental characteristics. European Management Journal 34(4): 386-399. 
Sieger P and Monsen E (2015) Founder, academic, or employee? A nuanced study of career choice intentions. Journal of Small Business Management (53): 30-57.

Sieger P, Fueglistaller U, Zellweger T and Braun I (2018) Global Student

Entrepreneurship 2018: Insights From 54 Countries. Report, University of St. Gallen/Bern.

Singer S, Herrington M and Menipaz E (2018) Global Entrepreneurship Monitor, Global Report 2017-2018. Report, Global Entrepreneurship Research Association.

Thorgren S, Sirén C, Nordström C and Wincent J (2016) Hybrid entrepreneurs' secondstep choice: The nonlinear relationship between age and intention to enter full-time entrepreneurship. Journal of Business Venturing Insights (5): 14-18.

Triandis HC and Gelfand MJ (2012) A theory of individualism and collectivism. In: van Lange PAM, Kruglanski AW and Higgins ET (eds) Handbook of theories of social psychology. Thousand Oaks: Sage Publications, 498-520.

Van Gelderen M, Kautonen T and Fink M (2015) From entrepreneurial intentions to actions: Self-control and action-related doubt, fear, and aversion. Journal of Business Venturing 30(5): 655-673.

Wagner JA and Moch MK (1986) Individualism-collectivism: Concept and measure. Group and Organization Studies 11(3): 280-304.

Westhead P and Solesvik MZ (2016) Entrepreneurship education and entrepreneurial intention: do female students benefit?. International Small Business Journal 34(8): 979-1003.

Yang KP, Hsiung HH and Chiu Y-J (2015) The comfort zone of the value circumplex for entrepreneurship: a structural analysis. Career Development International 20(6): $663-683$ 


\section{APPENDIX}

Table A1. Measurement model indicators

\begin{tabular}{|c|c|c|c|c|c|}
\hline \multicolumn{2}{|l|}{ Indicators } & Loadings & Alpha & C.R. & A.V.E. \\
\hline \multirow{4}{*}{ Entrepreneurial Intention } & ei1 & 0.904 & \multirow{4}{*}{0.938} & \multirow{4}{*}{0.939} & \multirow{4}{*}{0.843} \\
\hline & ei2 & 0.916 & & & \\
\hline & ei4 & 0.946 & & & \\
\hline & ei5 & 0.906 & & & \\
\hline \multirow{3}{*}{ Subjective Norms } & sn1 & 0.869 & \multirow{3}{*}{0.783} & \multirow{3}{*}{0.837} & \multirow{3}{*}{0.692} \\
\hline & sn2 & 0.883 & & & \\
\hline & sn3 & 0.735 & & & \\
\hline \multirow{6}{*}{ Perceived Behavioural Control } & $\mathrm{pbc1}$ & 0.737 & \multirow{6}{*}{0.850} & \multirow{6}{*}{0.858} & \multirow{6}{*}{0.570} \\
\hline & $\mathrm{pbc2}$ & 0.715 & & & \\
\hline & $\mathrm{pbc3}$ & 0.765 & & & \\
\hline & pbc4 & 0.765 & & & \\
\hline & pbc5 & 0.743 & & & \\
\hline & pbc6 & 0.800 & & & \\
\hline \multirow{5}{*}{ Personal Attitude } & pa1 & $0.349^{w}$ & \multirow{5}{*}{--} & \multirow{5}{*}{--} & \multirow{5}{*}{--} \\
\hline & pa3 & $0.254^{w}$ & & & \\
\hline & pa4 & $0.342^{w}$ & & & \\
\hline & pa5 & $0.112^{\mathrm{w}}$ & & & \\
\hline & pa6 & $0.422^{w}$ & & & \\
\hline
\end{tabular}

Notes: ${ }^{\mathrm{w}}$ Indicator weights for the formative construct (PA); C.R. = Composite Reliability; A.V.E. = Average Variance Extracted 
Table A2. Means, standard deviations, and correlations between latent variables for the full sample

\begin{tabular}{|c|c|c|c|c|c|c|c|c|c|c|c|c|c|c|}
\hline & & Mean & Std.Dev & 1. & 2. & 3. & 4. & 5. & 6. & 7. & 8. & 9. & 10. & 11. \\
\hline 1. & Conformity & 3.273 & 0.876 & 1.000 & & & & & & & & & & \\
\hline 2. & Tradition & 2.378 & 0.856 & 0.349 & 1.000 & & & & & & & & & \\
\hline 3. & Security & 3.482 & 0.827 & 0.157 & -0.025 & 1.000 & & & & & & & & \\
\hline 4. & Benevolence & 3.963 & 0.647 & -0.093 & -0.021 & -0.334 & 1.000 & & & & & & & \\
\hline 5. & Universalism & 3.955 & 0.738 & -0.251 & -0.013 & -0.275 & 0.366 & 1.000 & & & & & & \\
\hline 6. & PA & 3.631 & 1.081 & -0.172 & -0.224 & -0.030 & -0.118 & -0.156 & 1.000 & & & & & \\
\hline 7. & SNs & 3.550 & 1.397 & 0.093 & -0.029 & -0.009 & 0.059 & 0.005 & 0.321 & 1.000 & & & & \\
\hline 8. & PBC & 4.131 & 1.015 & -0.023 & -0.024 & 0.026 & -0.186 & -0.160 & 0.501 & 0.247 & 1.000 & & & \\
\hline 9. & EI & 3.332 & 1.691 & -0.106 & -0.007 & -0.053 & -0.120 & -0.162 & 0.527 & 0.214 & 0.505 & 1.000 & & \\
\hline 10. & Individ. Dummy & 0.494 & 0.501 & -0.323 & -0.329 & -0.192 & -0.297 & -0.424 & 0.264 & 0.073 & 0.152 & 0.230 & 1.000 & \\
\hline 11. & Country Dummy & 0.484 & 0.500 & -0.009 & -0.151 & 0.219 & -0.271 & -0.283 & 0.175 & -0.005 & 0.132 & 0.123 & 0.215 & 1.000 \\
\hline
\end{tabular}


Table A3. Means, standard deviations, and correlations between latent variables for the Spanish sample

\begin{tabular}{|c|c|c|c|c|c|c|c|c|c|c|c|c|c|}
\hline & & Mean & Std.Dev & 1. & 2. & 3. & 4. & 5. & 6. & 7. & 8. & 9. & 10. \\
\hline & Conformity & 3.194 & 0.844 & 1.000 & & & & & & & & & \\
\hline 2. & Tradition & 2.397 & 0.806 & 0.387 & 1.000 & & & & & & & & \\
\hline 3. & Security & 3.269 & 0.869 & 0.267 & 0.110 & 1.000 & & & & & & & \\
\hline 4. & Benevolence & 4.015 & 0.655 & -0.139 & 0.025 & -0.296 & 1.000 & & & & & & \\
\hline 5. & Universalism & 4.036 & 0.766 & -0.264 & -0.051 & -0.278 & 0.384 & 1.000 & & & & & \\
\hline 6. & PA & 3.426 & 1.114 & -0.098 & -0.174 & -0.080 & -0.117 & -0.170 & 1.000 & & & & \\
\hline 7. 5 & SNs & 3.553 & 1.411 & 0.005 & -0.067 & -0.032 & 0.070 & -0.011 & 0.441 & 1.000 & & & \\
\hline 8. $\mathrm{F}$ & PBC & 4.005 & 1.076 & 0.039 & -0.019 & 0.051 & -0.220 & -0.180 & 0.484 & 0.289 & 1.000 & & \\
\hline 9. & El & 3.128 & 1.630 & 0.018 & -0.009 & -0.081 & -0.083 & -0.200 & 0.524 & 0.287 & 0.464 & 1.000 & \\
\hline 10. 1 & Individ. Dummy & 0.390 & 0.489 & -0.306 & -0.324 & -0.250 & -0.317 & -0.444 & 0.196 & 0.075 & 0.050 & 0.159 & 1.000 \\
\hline
\end{tabular}


Table A4. Means, standard deviations, and correlations between latent variables for the UK sample

\begin{tabular}{|c|c|c|c|c|c|c|c|c|c|c|c|c|c|}
\hline & & Mean & Std.Dev & 1. & 2. & 3. & 4. & 5. & 6. & 7. & 8. & 9. & 10. \\
\hline 1. & Conformity & 3.358 & 0.903 & 1.000 & & & & & & & & & \\
\hline 2. & Tradition & 2.358 & 0.908 & 0.324 & 1.000 & & & & & & & & \\
\hline 3. & Security & 3.711 & 0.713 & 0.057 & -0.100 & 1.000 & & & & & & & \\
\hline 4. & Benevolence & 3.906 & 0.636 & -0.061 & -0.162 & -0.288 & 1.000 & & & & & & \\
\hline 5. & Universalism & 3.868 & 0.698 & -0.265 & -0.065 & -0.167 & 0.225 & 1.000 & & & & & \\
\hline 6. & PA & 3.853 & 1.001 & -0.235 & -0.215 & -0.042 & -0.085 & -0.094 & 1.000 & & & & \\
\hline 7. & SNs & 3.547 & 1.385 & 0.172 & 0.001 & 0.024 & 0.044 & 0.031 & 0.183 & 1.000 & & & \\
\hline 8. & PBC & 4.265 & 0.930 & -0.080 & 0.013 & -0.077 & -0.083 & -0.072 & 0.434 & 0.197 & 1.000 & & \\
\hline 9. & EI & 3.551 & 1.731 & -0.214 & 0.030 & -0.086 & -0.103 & -0.067 & 0.558 & 0.147 & 0.550 & 1.000 & \\
\hline 10. & Individ. Dummy & 0.605 & 0.490 & -0.352 & -0.294 & -0.255 & -0.176 & -0.322 & 0.328 & 0.077 & 0.222 & 0.262 & 1.000 \\
\hline
\end{tabular}


Figure 1: The Theory of Basic Human Values

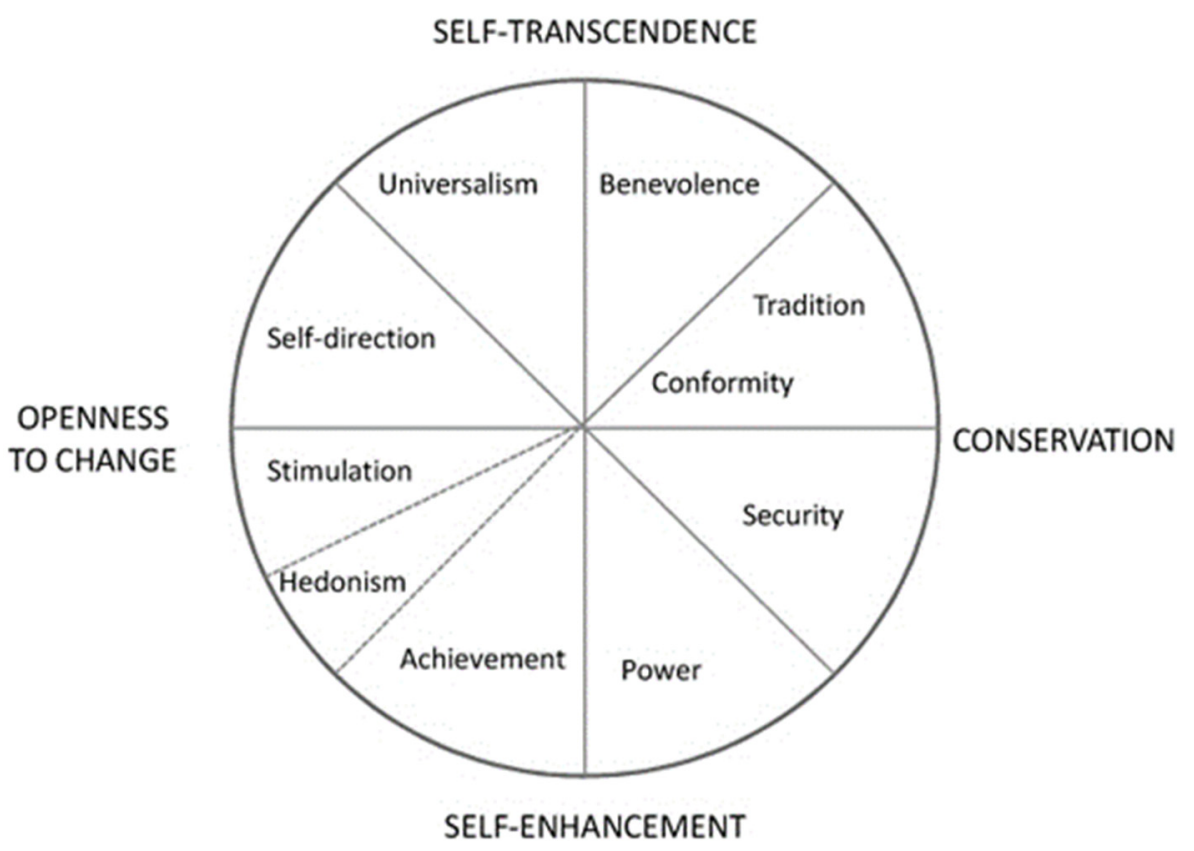

Source: Based on Schwartz $(1992,1994)$

Figure 2: Collectivistic personal values in the formation of entrepreneurial intentions

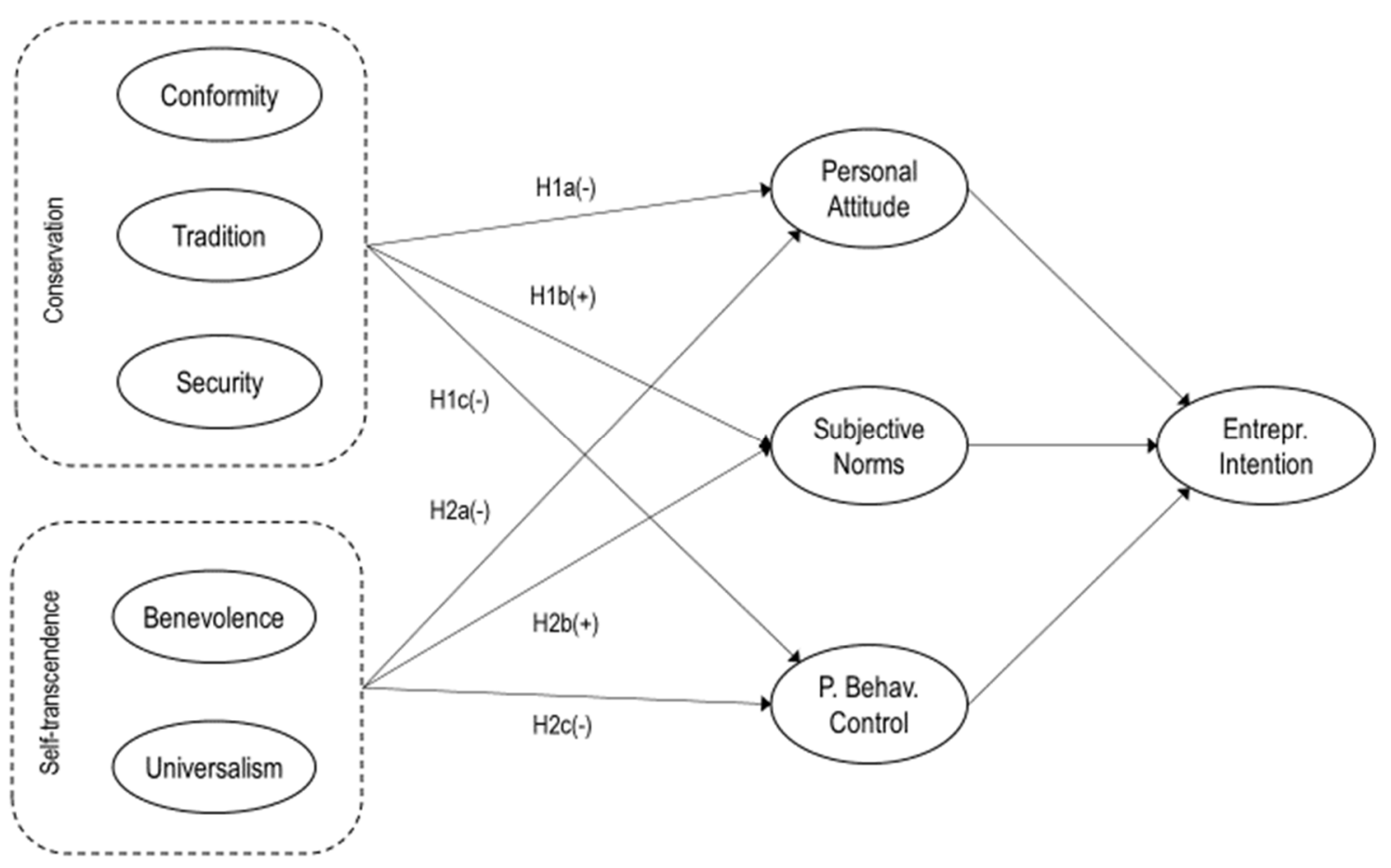


Figure 3: Results of the structural model with both individualism and country dummies

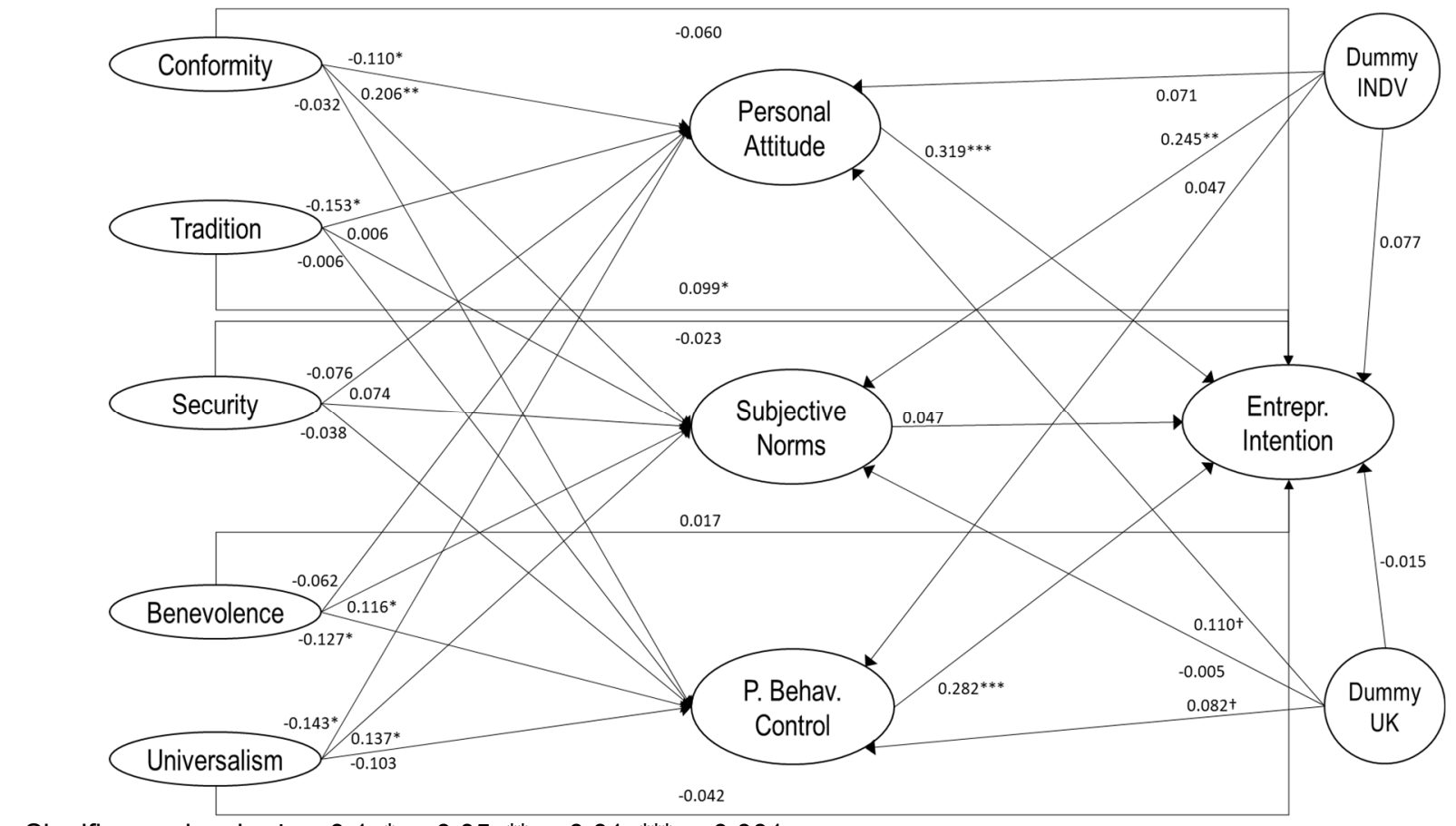

Significance levels: $\dagger p<0.1 ;{ }^{*} p<0.05 ;{ }^{* *} p<0.01 ;{ }^{* *} p<0.001$

Figure 4: Results of the structural model with individualism dummy

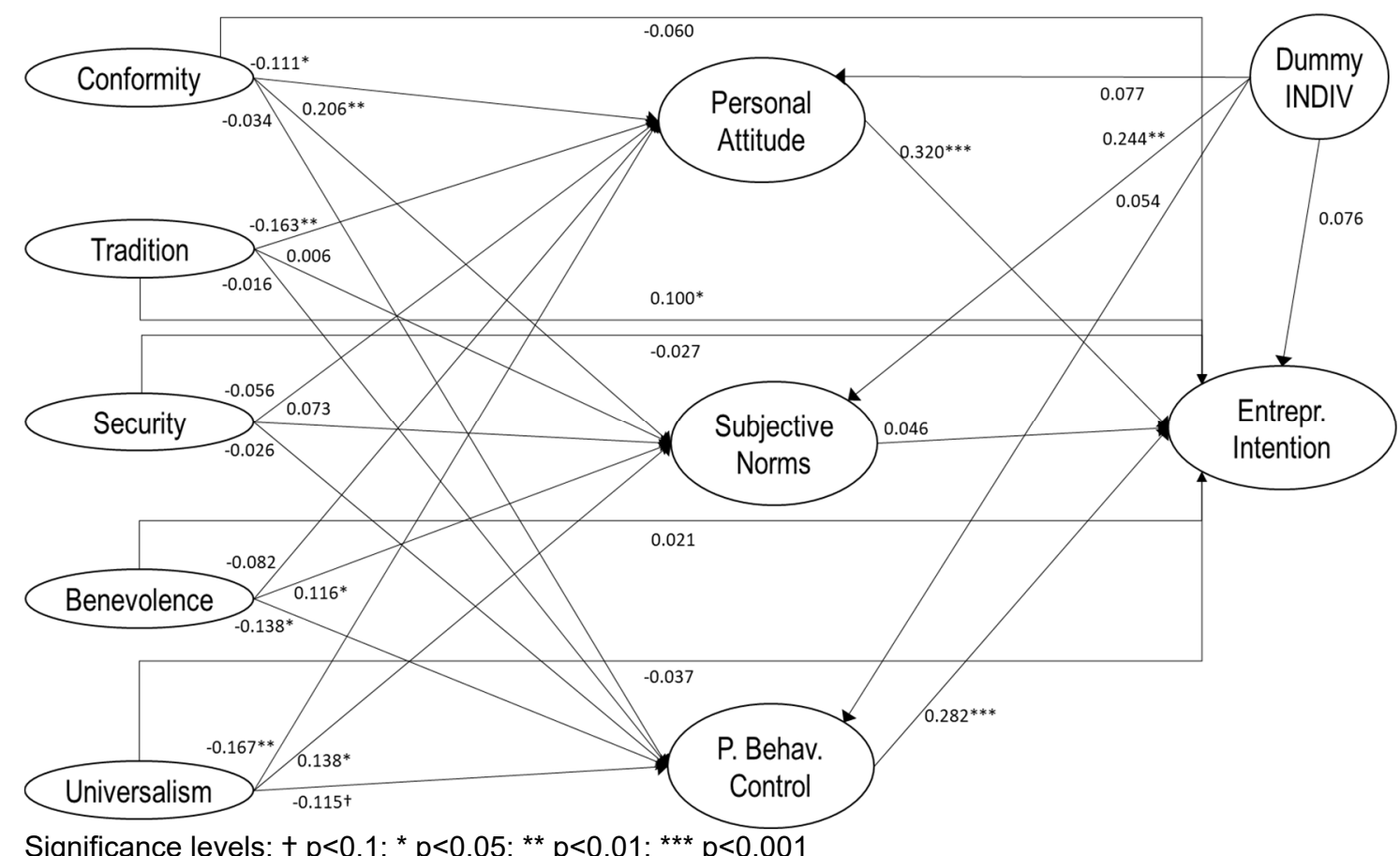

Significance levels: $\uparrow p<0.1 ;{ }^{*} p<0.05 ;{ }^{* *} p<0.01 ;{ }^{* * *} p<0.001$ 
Table 1: Descriptive analysis

\begin{tabular}{|c|c|c|c|c|c|c|}
\hline \multirow{2}{*}{ Descriptive Statistics } & \multicolumn{2}{|c|}{ UK $(N=200)$} & \multicolumn{2}{|c|}{ Spain $(N=213)$} & \multicolumn{2}{|c|}{ Both $(\mathrm{N}=413)$} \\
\hline & Mean & S.D. & Mean & S.D. & Mean & S.D. \\
\hline Age: (years) & 25.70 & 4.081 & 26.89 & 3.957 & 26.32 & 4.056 \\
\hline Gender: Female=0; Male $=1$ & 0.49 & 0.501 & 0.43 & 0.497 & 0.46 & 0.499 \\
\hline Entrepreneurship centre (yes $=1 ;$ no $=0$ ) & 0.08 & 0.264 & 0.12 & 0.327 & 0.10 & 0.299 \\
\hline Ever self-employed? (yes=1; no=0) & 0.29 & 0.453 & 0.14 & 0.353 & 0.21 & 0.410 \\
\hline Schooling level of the Father* & 3.07 & 0.980 & 2.54 & 1.304 & 2.80 & 1.186 \\
\hline Schooling level of the Mother* & 3.04 & 1.002 & 2.62 & 1.303 & 2.82 & 1.183 \\
\hline Family entrepreneur (yes $=1 ;$ no $=0$ ) & 0.65 & 0.480 & 0.62 & 0.486 & 0.63 & 0.483 \\
\hline Socio-Economic group ${ }^{* *}$ & 2.85 & 0.825 & 2.99 & 0.682 & 2.92 & 0.756 \\
\hline
\end{tabular}

Note: ${ }^{*} 1$ = Primary education; 2 = Secondary education; 3 = Vocational training; 4 = University; $5=$ Other; ${ }^{* *} 1=$ Lower; 2 = Lower-middle; 3 = Middle; 4 = Upper-middle; 5 = Upper 
Table 2: Path coefficients for the multigroup analysis

\begin{tabular}{|c|c|c|c|c|c|c|c|c|c|c|c|}
\hline \multirow{3}{*}{ D.INDIV->PA } & \multicolumn{3}{|c|}{ FULL SAMPLE } & \multicolumn{3}{|c|}{ SPAIN } & \multicolumn{3}{|c|}{ UK } & \multirow{2}{*}{\multicolumn{2}{|c|}{$\frac{\mid \text { SPAIN - UK } \mid}{\text { Path Difference. }}$}} \\
\hline & \multicolumn{2}{|c|}{ Path coeff. } & \multirow{2}{*}{\begin{tabular}{|l|} 
S. D. \\
0.072
\end{tabular}} & \multicolumn{2}{|c|}{ Path coeff } & \multirow{2}{*}{$\begin{array}{l}\text { S. D. } \\
0.112\end{array}$} & \multicolumn{2}{|c|}{ Path coeff. } & \multirow{2}{*}{$\begin{array}{c}\text { S. D. } \\
0.101\end{array}$} & & \\
\hline & 0.077 & & & -0.040 & & & 0.219 * & & & 0.259 & \\
\hline D.INDIV->SNs & 0.244 & $* *$ & 0.073 & 0.137 & & 0.104 & 0.356 * & *** & 0.096 & 0.220 & $\dagger$ \\
\hline D.INDIV->PBC & 0.054 & & 0.079 & -0.169 & & 0.114 & $0.250 *$ & * & 0.100 & 0.418 & ** \\
\hline D.INDIV->E.I. & 0.076 & & 0.060 & 0.046 & & 0.088 & 0.054 & & 0.083 & 0.007 & \\
\hline Conformity -> PA & -0.111 & * & 0.056 & -0.093 & & 0.100 & -0.111 & & 0.087 & 0.018 & \\
\hline Conformity -> SNs & 0.206 & ** & 0.070 & 0.092 & & 0.100 & 0.341 * & *** & 0.097 & 0.249 & * \\
\hline Conformity->PBC & -0.034 & & 0.057 & -0.061 & & 0.091 & 0.006 & & 0.082 & 0.067 & \\
\hline Conformity -> E.I. & -0.060 & & 0.054 & 0.016 & & 0.070 & -0.110 & & 0.083 & 0.126 & \\
\hline Tradition -> PA & -0.163 & $* *$ & 0.061 & -0.150 & & 0.104 & -0.094 & & 0.089 & 0.056 & \\
\hline Tradition $->$ SNs & 0.006 & & 0.055 & -0.034 & & 0.084 & 0.082 & & 0.078 & 0.116 & \\
\hline Tradition $->$ PBC & -0.016 & & 0.060 & -0.065 & & 0.081 & 0.087 & & 0.083 & 0.153 & $\dagger$ \\
\hline Tradition -> E.I. & 0.100 & * & 0.044 & 0.047 & & 0.059 & $0.145 *$ & * & 0.066 & 0.099 & \\
\hline Security -> PA & -0.056 & & 0.062 & -0.136 & & 0.096 & -0.021 & & 0.090 & 0.115 & \\
\hline Security $->$ SNs & 0.073 & & 0.062 & 0.017 & & 0.086 & $0.169 \dagger$ & $\dagger$ & 0.090 & 0.152 & \\
\hline Security $->$ PBC & -0.026 & & 0.066 & -0.090 & & 0.098 & 0.000 & & 0.087 & 0.090 & \\
\hline Security $\rightarrow$ E.I. & -0.027 & & 0.047 & -0.041 & & 0.070 & -0.020 & & 0.066 & 0.021 & \\
\hline Benev. -> PA & -0.082 & & 0.056 & -0.085 & & 0.092 & -0.062 & & 0.076 & 0.022 & \\
\hline Benev. -> SNs & 0.116 & * & 0.053 & 0.103 & & 0.078 & $0.127 \dagger$ & $\dagger$ & 0.073 & 0.024 & \\
\hline Benev. -> PBC & -0.138 & * & 0.064 & -0.211 & * & 0.094 & -0.026 & & 0.073 & 0.185 & $\dagger$ \\
\hline Benev. -> E.I. & 0.021 & & 0.049 & 0.058 & & 0.066 & -0.012 & & 0.066 & 0.070 & \\
\hline Univers. -> PA & -0.167 & $* *$ & 0.064 & -0.230 & * & 0.104 & -0.062 & & 0.089 & 0.167 & \\
\hline Univers. -> SNs & 0.138 & * & 0.069 & 0.053 & & 0.095 & $0.229 *$ & & 0.095 & 0.176 & $\dagger$ \\
\hline Univers. -> PBC & -0.115 & $\dagger$ & 0.063 & -0.230 & * & 0.092 & 0.023 & & 0.077 & 0.253 & * \\
\hline Univers. -> E.I. & -0.037 & & 0.052 & -0.066 & & 0.081 & -0.024 & & 0.066 & 0.042 & \\
\hline PA -> E.I. & 0.320 & $* * *$ & 0.052 & 0.350 & $* * *$ & 0.086 & 0.331 * & *** & 0.070 & 0.019 & \\
\hline SNs -> E.I. & 0.046 & & 0.043 & 0.055 & & 0.069 & 0.039 & & 0.059 & 0.016 & \\
\hline PBC -> E.I. & 0.282 & $* * *$ & 0.050 & 0.248 & $* *$ & 0.074 & 0.332 * & *** & 0.067 & 0.084 & \\
\hline
\end{tabular}

Significance levels: $\dagger p<0.1 ;{ }^{*} p<0.05 ;{ }^{* *} p<0.01 ;{ }^{* * *} p<0.001$ 
Authors' bios:

Juan Alberto Hueso is a PhD student at the University of Seville. He got his bachelor's degree in Economics. His research interests are related to personal values in the identity formation of entrepreneurs and to the entrepreneurial intention. Juan Alberto has participated in projects sponsored by the Spanish national government (ELITE) and the OECD. He is actively participating in the European University Network on Entrepreneurship (ESU).

Inmaculada Jaén holds a PhD degree in Economics from the University of Seville. Inmaculada is an Assistant Professor of Economics in the Department of Applied Economics, University of Seville, and a member of the research group "SMEs and Economic Development". She has participated in several research projects, funded by the regional and national administrations, as well as the OECD. Dr. Jaén is taking part in the ELITE project (Ref.: ECO2016-75655-P) financed by the Ministry of Economy and Competitiveness in Spain. She has published a number of contributions in academic journals and edited books.

Francisco Liñán is a Professor in Entrepreneurship and innovation at Anglia Ruskin University (United Kingdom), as well as Associate Professor at the University of Seville (Spain). Prof. Liñán's research interests include entrepreneurship, the entrepreneurial process and entrepreneurship education. His work has been published in journals such as International Small Business Journal, Entrepreneurship Theory and Practice, Entrepreneurship and Regional Development and Small Business Economics. He has participated in projects funded by the Spanish national government, the EU and the OECD. He is Research Editor at Entrepreneurship Education \& Pedagogy and Editorial Board Member at Entrepreneurship Theory and Practice and International Entrepreneurship and Management Journal.

Whysnianti Basuki holds a MSc in Social Sciences in Accounting and Management Science from the University of Southampton, an MBA and a PhD from Southampton Solent University. Her PhD topic was 'gender factors in strategic managerial behaviour in small and medium-sized enterprises'. Dr. Basuki is an active member of the ESU Network on Entrepreneurship and her research interests include entrepreneurship and gender. 